\title{
O corpo da deficiência sob o olhar docente no Atendimento Educacional Especializado
}

\author{
The disability body under the teacher's view in
}

Specialized Educational Assistance

El organismo de discapacidad bajo la mirada del docente en la Asistencia Educativa Especializada

LIZIANE DA SilVA BARBOSA (iDa

Helena Venites Sardagna (D)

\section{Resumo}

Este artigo compõe-se do recorte de uma pesquisa que discute sobre o olhar docente no Atendimento Educacional Especializado (AEE) e as expectativas em relação aos estudantes, problematizando como professores desse serviço de apoio criam/inventam estratégias pedagógicas que incidem no corpo e nas condutas dos estudantes com deficiência, em escolas da Região Litoral Norte do Rio Grande do Sul. Objetivou-se compreender e analisar governamentos engendrados nas práticas que incidem sobre os estudantes nos atendimentos em espaços denominados Salas de Recursos Multifuncionais. Buscou-se inspiração em noções foucaultianas da análise do discurso, como jogos estratégicos, sob a grade de inteligibilidade da governamentalidade enquanto arte de governar as condutas e os modos de agir socialmente, no contexto da biopolítica. O exercício analítico permitiu a organização dos resultados em eixos temáticos, quais sejam: i) Saberes especializados: o (bio)poder da medicina e da psicologia na educação; ii) As verdades sobre a família: o desencaixe em relação às expectativas do especialista; iii) A deficiência: a distinção entre normal e anormal como marcador do corpo. Conclui-se que o AEE é um campo de disputa de poderes e saberes diversos que produzem desejos e vontades, e inventam verdades que transformam os

\footnotetext{
a Universidade Estadual do Rio Grande do Sul, Porto Alegre, RS, Brasil. Mestra em Educação, e-mail: barbosalizzi@gmail.com

b Universidade Estadual do Rio Grande do Sul, Porto Alegre, RS, Brasil. Doutora em Educação, e-mail: helena-sardagna@uergs.edu.br
} 
sujeitos com deficiência em um corpo teórico - um corpo imaginário, manipulável e superador contumaz.

Palavras-chave: Olhar do professor. Corpo da deficiência. Atendimento Educacional Especializado.

\begin{abstract}
This article is composed of a survey that discusses the teaching perspective of specialized educational services (AEE) and expectations regarding students, discussing how teachers in this support service create / invent pedagogical strategies that affect the body and behaviors of students with disabilities, in schools in the North Coast region of Rio Grande do Sul. The objective was to understand and analyze the governments engendered in the practices that affect students in services in spaces called Multifunctional Resource Rooms. He sought inspiration in Foucault's notions of discourse analysis as strategic games, under the intelligibility grid of governmentality, as the art of governing the conduct and ways of acting socially, in the context of biopolitics. The analytical exercise allowed the organization of the results in thematic axes, which are: Specialized knowledge: the (bio) power of medicine and psychology in education; The truths about the family: mismatch with the specialist's expectations; Disability: the distinction between normal and abnormal as a body marker. It concludes that the AEE is a field of dispute of powers and diverse knowledge that produce desires, desires and invent truths that transform subjects with disabilities into a theoretical body. An imaginary body, manipulable and contumacious.
\end{abstract}

Keywords: The teacher's look. Disability body. Specialized Educational Service.

\title{
Resumen
}

Este artículo está compuesto por una encuesta que analiza la perspectiva docente de los servicios educativos especializados (AEE) y las expectativas de los estudiantes, discutiendo cómo los docentes de este servicio de apoyo crean / inventan estrategias pedagógicas que afectan el cuerpo y las conductas de estudiantes con discapacidad, en escuelas de la región de la Costa Norte de Rio Grande do Sul. El objetivo fue comprender y analizar los gobiernos engendrados en las prácticas que afectan a los estudiantes en los servicios en los espacios denominados Salas de Recursos Multifuncionales. Buscó inspiración en las nociones de Foucault del análisis del discurso como juegos estratégicos, bajo la trama de inteligibilidad de la gubernamentalidad, como el arte de gobernar la conducta y las formas de actuar socialmente, en el contexto de la biopolítica. El ejercicio analítico permitió la organización de los resultados en ejes temáticos, los cuales son: Conocimientos especializados: el (bio) poder de la medicina y la psicología en la educación; Las verdades sobre la familia: desajuste con las expectativas del especialista; Discapacidad: la distinción entre normal y anormal como marcador corporal. Se concluye que la AEE es un campo de disputa de poderes y saberes diversos que producen deseos, anhelos e inventan verdades que transforman a los sujetos con discapacidad en un cuerpo teórico. Un cuerpo imaginario, manipulable y contumaz.

Palabras clave: La mirada del profesor. Cuerpo de discapacidad. Servicio Educativo Especializado. 


\section{Introdução}

O presente estudo parte da problematização de discursos e narrativas que atravessam os atendimentos e a prática pedagógica nas Salas de Recursos Multifuncionais (SRM) acerca dos desafios relatados por professores na ação docente com os alunos. A reflexão inicial também agrega os constantes relatos dos professores em relação à vulnerabilidade social dos estudantes, a qual se configura como fator da não aprendizagem. Esses dois aspectos foram essenciais para o desenho de uma pesquisa, cujo recorte constituiu este artigo.

O contexto da pesquisa foi a Região Praieira do Litoral Norte do estado do Rio Grande do Sul (RS), composta por 21 municípios. Destes, seis municípios costeiros foram alvo deste estudo: Balneário Pinhal, Cidreira, Tramandá, Imbé, Osório e Xangri-lá. Os dados foram coletados por meio de instrumentos descritos na próxima Seção com sete professores do Atendimento Educacional Especializado (AEE) que atuam nos municípios citados. Entre os participantes, apenas um é do sexo masculino. A pesquisa contou com um professor de cada município, exceto Balneário Pinhal, onde participaram dois professores.

A região em questão tem característica peculiar pelas relações sociais e políticas marcadas pela sazonalidade. Durante a baixa temporada, a população oscila entre 13 e 24 mil habitantes, aproximadamente. Já na alta temporada, a população se multiplica, podendo alcançar os 150 mil veranistas. Esses extremos deixam marcas culturais e financeiras, que produzem uma noção equivocada de falta de possibilidades e de atrativos econômicos e desperta desejos para realidades urbanas muito diversas às realidades praieiras, repercutindo no campo da educação local.

O estudo é entrelaçado em diferentes nuances e conceitos que permitem questionamentos e vontades de construir um conhecimento significativo para as comunidades educadoras da região. Foi possível evidenciar e compreender como são conduzidas as práticas dos professores do AEE e trazer à tona as implicações dessas práticas na efetivação da aprendizagem dos estudantes.

O referencial teórico buscou inspiração em conceitos foucaultianos, especialmente o de governamentalidade, que foi operada como "uma proposta de grade de análise para essas relações de poder" (FOUCAULT, 2008a, p. 258), ou seja, 
como uma lente que visibiliza o funcionamento das políticas públicas para a educação inclusiva. Esse olhar concebe que as realidades, assim como as práticas docentes, são invenções que se constituem em verdades as quais incidem sobre os comportamentos das populações, numa relação de poder contínua.

Parte-se do pressuposto de que as práticas do AEE seguem um conjunto de normativas previstas nos regulamentos legais e em diretrizes. Contudo, evidencia-se que, em cada contexto, há estratégias de invenção que vão constituindo modos de olhar para o sujeito com deficiência, recorrentemente direcionando esse olhar para a conduta e para o corpo dos estudantes com deficiência.

Nesse sentido, o estudo questionou: como professores do Atendimento Educacional Especializado da Região Litoral Norte do Rio Grande do Sul inventam estratégias pedagógicas que incidem sobre as pessoas com deficiência no espaço escolar?

O estudo analítico também considerou as práticas na relação com o discurso, em suas regularidades que definem o dito e o não dito, e as circunstâncias em que se dá o dito, limitando o acontecimento e o acaso (FOUCAULT, 2002a). Toma-se o discurso como "jogos estratégicos, de ação e de reação, de pergunta e resposta, de dominação e de esquiva, como também de luta” (FOUCAULT, 1974, p. 6).

Nessa perspectiva, as práticas — tanto na educação quanto fora dela — são processos de condução de condutas, engendrados para controlar e regulamentar as populações, a saber, os corpos e as condutas dos estudantes com deficiência, e estão atreladas a jogos de poder. A governamentalidade consiste na arte de governar as condutas e os modos de agir socialmente de uma população.

A noção de biopolítica foi tomada na relação com o poder de controle dos vivos por meio da subjetivação e do convencimento dos sujeitos, como uma estrutura que sustenta as políticas educacionais atuais como reguladoras das populações (FOUCAULT, 2001). No contexto pesquisado, as políticas inclusivas ainda estão em processo de consolidação, e as estratégias pedagógicas direcionadas às pessoas com deficiência são evidenciadas em uma diversidade de dizeres que ajudam a trazer à tona discursos e governamentos engendrados a partir do AEE.

O termo "governamento" é empregado a partir da proposição de Veiga-Neto (2005), que, ao discutir a noção foucaultiana de governamentalidade, propõe o emprego da noção de governamento. Isso se dá porque Foucault utilizou em sua 
produção escrita duas palavras distintas em francês (gouverne e gouvernement), mas ambas vinham sendo traduzidas em língua portuguesa da mesma forma: governo. A fim de explicitar a diferença da noção de Governo (em letra maiúscula), entendido como "a instituição do Estado", o autor propõe governamento, que denota "instrumento de ação" e "noção coletiva" (VEIGA-NETO, 2005, p. 84).

\section{Oficina analítica}

Os dados foram coletados a partir da aplicação de três instrumentos que se constituíram em um conjunto de ferramentas: um grupo virtual de bate-papo; um questionário de livre evocação de palavras; uma entrevista gravada. A intenção foi oportunizar lugares de fala diferentes aos participantes, que foram convidados a participar, responder e compartilhar seus afazeres, entendimentos e práticas.

O grupo virtual foi composto inicialmente pelos 16 participantes que se voluntariaram, a partir de convite direto, a responder perguntas sobre suas práticas no serviço de AEE. Contudo, conforme discriminado acima, sete professores de AEE participaram de todas as etapas, constituindo os sujeitos da pesquisa. Estes serão identificados como "Professor(a)", seguido do nome da cidade de atuação e do ano de participação, de modo a resguardar suas identidades. Alguns professores optaram por participar apenas pelo grupo, outros preferiram somente participar das entrevistas e responder ao questionário. A articulação com o grupo participante foi realizada por uma das pesquisadoras, e esse movimento ocorreu sem a sua ingerência.

No grupo virtual, foi proposto aos participantes o seguinte desafio: "Descreva como são realizados os atendimentos durante uma semana, a sua escolha”. Esse movimento permitiu evidenciar o AEE como um ritual que já aponta sinais de uma padronização, carregada por saberes e ações dos campos de saber da medicina e da psicologia, sendo regulamentado por uma legislação prescritiva, que restringe um campo de atuação e constitui efeitos desses saberes sobre aqueles para os quais as práticas se dirigem. Para a entrevista, seguiu-se um roteiro de sete questões acerca da função do AEE, das estratégias desenvolvidas nesse serviço de apoio, da relação com os setores da escola e com as famílias. Assim, buscou-se evidenciar as recorrências discursivas que se entrelaçam às práticas engendradas no AEE. 
O questionário de livre evocação partiu de uma pergunta durante os encontros para a entrevista, com inspiração na técnica de livre evocação de palavras, instigando o participante a responder: "Para você o AEE é...". Esse questionário foi aplicado com o intuito de perceber a ordem e a importância das palavras que envolvem esse campo de saber e como são pronunciadas e constituídas nas subjetividades dos professores participantes, antes que tenham tempo de elaborar respostas prontas.

A partir do questionário, foi realizada uma associação de palavras inspirada na técnica de livre associação de palavras. É importante destacar que essa técnica, embora projetiva, segundo Jung (1905 apud RAPAPORT, 1965), tem como principal característica revelar os aspectos mais subjetivos do indivíduo, sua personalidade e/ou suas representações sobre determinado objeto - não são essas representações que interessam aos objetivos desta pesquisa.

Foram muitas as palavras e frases usadas para definir como o serviço de AEE se configura nas escolas, e todas demonstram que o cenário ainda é de implementação e de insegurança. Pode-se perceber que há influência direta do texto da Política Nacional da Educação Especial, bem como uma incerteza sobre o que afirmar. Os participantes responderam com cuidado para evitar denuncismos, mas ficou evidente que o serviço ainda tem muito a fazer.

As palavras apontam, em maioria, para um desconforto e para uma vontade de superação, de consolidação e — por que não dizer — de padronização do serviço. Também emergem desencaixes em relação à ordem do discurso vigente: o imperativo de incluir e de vender a superação a todo e qualquer sujeito com deficiência. Esse discurso prescreve que esses sujeitos precisam ser disciplinados e subjetivados para serem produtivos, segundo ditames dessa ordem. A partir das figuras de superatletas amputados, professores autistas ou com síndrome de Down, entre outros profissionais com deficiência bem-sucedidos, universaliza-se uma ideia de que isso é possível a todos e que a responsabilidade de fazer isso acontecer é da escola, em especial dos professores de AEE. A produção e consolidação desse discurso pode ser aproximada à noção de que "o discurso nada mais é do que a reverberação de uma verdade nascendo diante de seus próprios olhos [...]" (FOUCAULT, 2002a, p. 48-49).

O imperativo da inclusão, por meio das políticas públicas e das narrativas dos artefatos midiáticos e culturais, produz um sujeito da deficiência incompatível com o 
sujeito que se apresenta na escola. Tal escola ainda funciona sob a égide da normação e da normalização. Lopes e Rech (2013) aludem a Foucault e descrevem que "A normação deriva diretamente da norma, ou seja, é a partir de uma norma universal e tomada a priori às relações entre os sujeitos que se determina o normal e o anormal" (LOPES; RECH, 2013, p. 212). Já “a operação de normalização vai consistir em fazer essas diferentes distribuições de normalidade funcionarem umas em relação às outras e [em] fazer de sorte que as mais desfavoráveis sejam trazidas às que são mais favoráveis" (FOUCAULT, 2008b, p. 82-83).

Desse modo, os desencaixes ocorrem no confronto entre o que é possível ou desejável realizar na escola, com todos os seus padrões e réguas normativas, e aquilo que as mídias divulgam incessantemente, materializado em casos pontuais e experiências exitosas que buscam construir um novo padrão de normalidade ou de múltiplas normalidades. A cada repetição dos prescritos da legislação, evidenciados nos dados a seguir, surge uma nova condição de possibilidade para esse novo sujeito da deficiência: aprendente, superador, dócil e, acima de tudo, produtivo. Os dados evidenciam uma atestação da funcionalidade do serviço de AEE a partir da lógica proposta pela legislação, assim como fazem emergir desses regulamentos uma prática pedagógica que se institucionaliza na busca pela consolidação das SRM como ferramentas de equiparação educativa entre normais e anormais.

\section{Saberes especializados: o (bio)poder da medicina e da psicologia na educação}

Partimos do pressuposto de que a produção de verdade a respeito do AEE ainda está em processo de instituição e que há uma constante disputa de espaço entre o discurso pedagógico e o discurso de saúde (da medicina). Essa associação hierarquizada de saberes para controlar e disciplinar os estudantes com deficiência tem o "objetivo de controlar esses sujeitos, aproximando-os ao máximo do normal" (LOCKMANN, 2013, p. 140). A hierarquização desses saberes se configura a partir de uma recorrência de linguagem própria do saber médico, surgida nos dizeres dos participantes em vários momentos da conversa. 
Tendo essa afirmação como ponto de partida, é possível denotar que os dizeres dos participantes são atravessados por saberes que permeiam o campo da educação, mas que pertencem a outros campos de saber, ou seja, os saberes que se organizam como as verdades do campo das psicologias: os saberes Psi. Nesse sentido, buscamos apoio no registro de Foucault:

Cada sociedade tem seu regime de verdade, sua "política geral" de verdade: isto é, os tipos de discurso que ela acolhe e faz funcionar como verdadeiros; os mecanismos e as instâncias que permitem distinguir os enunciados verdadeiros dos falsos, a maneira como se sanciona uns e outros; as técnicas e os procedimentos que são valorizados para a obtenção da verdade; o estatuto daqueles que têm o encargo de dizer o que funciona como verdadeiro (FOUCAULT, 2001, p. 12).

A seguir, apresentam-se excertos de dizeres de participantes nos quais se evidencia de forma recorrente uma linguagem própria do campo da medicina e das psicologias:

Nível de QI , diagnóstico, apoio de fono, de psico, de neurologistas..., só que a gente tem que observar a parte física deles, o neurológico [...] (Professora Balneário Pinhal, 2019); anamnese (Professora Imbé, 2019); antes eles aceitavam parecer de psicólogo, agora não aceitam mais, tem que ser só de médicos [...], tem que ter o tal do CID [...], eu sempre digo que a DI [deficiência intelectual] é a mais difícil de ser comprovada, porque demanda de médicos, de psicólogos, de tudo não é visível [...]; eu não posso questionar o que o médico diz [...], ela tem uma limitação [...], o TDAH não para, então tudo se torna mais difícil [...] (Professora Osório, 2019); às vezes não é nem aprender a ler e escrever, mas sim o emocional [...], tem descrições de baixa autoestima, a gente fala com a orientação e com a família [...] (Professora Balneário Pinhal, 2019); eu vejo, assim, que autoestima deles é muito baixa, eu sinto bastante isso [...] (Professor Cidreira, 2019); ainda estou à procura dessas ferramentas para me auxiliar; 10 com laudo e mais 8 que estão em investigação (Professora Xangri-Lá, 2019).

Nota-se, nesses excertos, que o sujeito com deficiência é narrado pelo especialista, por meio de saberes médicos, inventando um enunciado que toma para o AEE uma forma mais terapêutica do que pedagógica — ainda assim, constitutiva da prática pedagógica no espaço das SRM. Os professores balizam suas falas em saberes outros, em busca de validar o serviço prestado no AEE, e isso faz emergir um regime de verdade, constituindo esse espaço como um lugar de regulação e normatividade terapêutica que tenta igualar sujeitos com deficiência e sem deficiência.

Essa prática "aproxima os sujeitos da sociedade para constituí-los como uma população que tem suas regularidades, seus riscos próprios, suas ameaças, mas que, estando perto, e conhecida, pode ser controlada e governada" (LOPES et al., 2010, p. 13). Esse controle e governo passa pela construção de registros e regulamentos que 
buscam apagar as diferenças, em um processo de trazer os estudantes com deficiência o mais próximo da curva da normalidade.

É interessante perceber que a busca por igualar os sujeitos escolares produz também um discurso que denota muito mais impossibilidades e limites do que a superação imposta pelos discursos midiáticos. Esse discurso assume a limitação do próprio serviço e submete as práticas pedagógicas aos saberes de outros setores ligados à saúde, condicionando o sucesso ou insucesso dos atendimentos à frequência dos procedimentos e das prescrições médicas. O professor do AEE torna-se um acionador de engrenagens da biopolítica, no sentido de garantir que os estudantes com deficiência entrem e permaneçam no sistema. Mais que isso, "passa a ser também um operador eficaz na sociedade de seguridade, produzindo efeitos sobre a coletividade” (LOCKMANN, 2013, p. 135), reforçando assim o jogo entre liberdade, segurança e produtividade.

\section{As verdades sobre a familia: o desencaixe em relação às expectativas do especialista}

O imperativo da inclusão trouxe à tona, mais uma vez, o aluno padrão, constituído no contexto escolar, que aprende ao mesmo tempo, que corresponde a comportamentos e estágios homogêneos, referenciado a uma norma e suas curvas padrões de normalidade. Nesse contexto, é preciso dar um passo atrás na história e olhar para a construção da família. Pode-se usar três registros históricos: a invenção da família; a invenção da escola e a invenção do especialista. A invenção da família se deu num tempo em que era necessário construir estratégias para controlar a população trabalhadora desde a infância. Segundo Varela e Uria (1992, p. 13):

Não é casual que as intervenções tendentes a instaurar nas classes trabalhadoras o sentimento de família conjugal coincidam precisamente com a promulgação da obrigatoriedade escolar. $\mathrm{O}$ operário, que, pacientemente, há de se fazer proprietário de sua casa e de se preocupar pelo bem-estar de sua família estará imunizado contra os vírus da dissolução social.

Então, a invenção da escola obrigatória se deu no mesmo tempo histórico em que a família nuclear cristã também tornou-se uma instituição. Assim, passou a capturar a infância originada na classe trabalhadora e instruí-la para manter a ordem 
vigente, inventando desejos de estabilidade financeira e possibilidades de um futuro em melhor posição social. Nesse cenário, a família passou a ter compromissos em manter e cumprir com a ordem do dia e, nesse contexto social, com a escola e com os regulamentos criados por ela em nome da educação dos filhos, numa rede muito bem engendrada de moral, bons costumes e escolarização.

Foucault afirmou que "Todo sistema de educação é uma maneira política de manter ou modificar a apropriação dos discursos, com os saberes e poderes que eles trazem consigo" (FOUCAULT, 2002a, p. 44). É importante entender que os movimentos desse tempo histórico produziram alguns efeitos e também discursos que perduram até o momento contemporâneo, a exemplo do papel de educar da família e da sua participação na vida escolar, sendo a família muitas vezes apontada como a causadora dos fracassos escolares. Assim, ainda se espera uma família submissa aos discursos da escola e preocupada com os deveres de um sistema que busca uma economia de poder sobre as populações.

Com a invenção dessa escola, também ocorreu a invenção dos especialistas e das pedagogias. Varela (2000) contribui com seus estudos sobre a maquinaria escolar quando registra que o surgimento do especialista (aqui, cabe destacar, não o especialista contemporâneo, mas aquele que emergiu dos primeiros movimentos da escola obrigatória) como uma espécie de regulador das condutas, uma função além do disciplinamento. Trata-se de uma regulação e um governamento que se dão por meio das relações de poder e saber. De acordo com Varela:

\begin{abstract}
Os saberes pedagógicos são o resultado, em boa parte, da articulação dos processos que levaram à pedagogização dos conhecimentos e à disciplinarização interna dos saberes. Estas classificações e hierarquias de sujeitos e saberes costumam, em geral, ser aceitas como algo dado, como naturais, razão pela qual seu reconhecimento contribui para aprofundar sua lógica de funcionamento. A pedagogia racionaliza, em geral, uma certa organização escolar e certas formas de transmissão sem questionar nunca a arbitrariedade dessa organização, nem tampouco o estatuto dos saberes que são objeto da transmissão (VARELA, 2000, p. 93).
\end{abstract}

Essa racionalização contribuiu para a invenção desse profissional especialista, que foi forjado para cumprir uma meta escolar de disciplinar, governar e sequestrar as crianças das suas famílias. Nesse sentido, ainda nos dias atuais podem-se apontar duas possíveis evidências dos desencaixes entre escola, família e especialistas: as 
mudanças contínuas dos modelos familiares e a falta delas na formação dos professores especialistas.

Os professores esperam das famílias uma participação servil e entendem que, quanto mais terapias e medicações são ministradas, mais fácil será o trabalho de equiparação de aprendizagem. Então surge uma fala comum que designa à família dois rótulos: as difíceis e as maravilhosas. Nos ditos a seguir, o professor faz referência às duas. Nesse ínterim, percebem-se categorizações de famílias que correspondem aos dois modelos: aqueles que se ocupam das deficiências e seus tratamentos, e aqueles que apenas levam à escola ou nem isso. Este último é retratado no seguinte excerto: “Tem pais maravilhosos e outros precisam ser chamados para muitas conversas, outros não querem saber de nada e não aceitam seu filho ser diferente, enfim precisa fazer um trabalho de conquista de confiança e acolher estas famílias" (Professora Imbé, 2019).

A premissa de incluir a todos, sem distinção, transforma o ambiente escolar para trabalhar com a diversidade de alunos, além da diversidade de culturas e níveis de aprendizagem. Essa ordem do dia vale para todos; contudo, a carga de valores escolares ainda reside nesses tempos em que a instituição é disciplinadora e reguladora dos corpos e das ideias. Dessa forma, organizar o governamento de corpos e mentes que por séculos estiveram às margens dos padrões estabelecidos cria muitos desencaixes, pois se trata de operar com dois poderes em concomitância. Enquanto o poder disciplinar subjetiva os especialistas desde a formação inicial, o biopoder corresponde às novas estratégias de inclusão em nome da segurança da população. Assim, é oportuno lembrar:

O poder funciona e se exerce em rede. Nas suas malhas, os indivíduos não só circulam mas estão sempre em posição de exercer este poder e de sofrer sua ação; nunca são o alvo inerte ou consentido do poder, são sempre centros de transmissão. Em outros termos, o poder não se aplica aos indivíduos, passa por eles (FOUCAULT, 2001, p. 193).

Olhando para os dados, pode-se inferir que existe uma expectativa sobre a ação familiar que deve ter o papel ideal de ser parceira da escola, de saber tudo sobre a deficiência da criança e, acima de tudo, de cumprir os horários estabelecidos e estar presente em todas as instituições de atendimento à criança. Em outras palavras, há uma incidência contínua do biopoder sobre essa parcela da população para que permaneça 
na malha biopolítica. Então, estabelece-se um jogo de responsabilidades negligenciadas e, com ele, juízos de valor moral. Conforme o excerto a seguir, existem diversos desencaixes que se sustentam em discursos que tornaram as pessoas com deficiências invisíveis para a escola e para a sociedade por muito tempo. Para o participante:

Tem algumas famílias, que é muito difícil, por exemplo, tem uma aluna da tarde que é terrível, assim, a impressão que me dá é que eles não aceitam a condição da menina e que querem deixar ela escondidinha dentro de casa. [...] Não sei se é por conta dessa questão de ter deficiência, ou se é porque a família quer meio que esconder, também (Professora Cidreira, 2019).

Então, há um entendimento de que é necessário para essa família permitir que a filha estude, receba os atendimentos e, mais que isso, retire-a do esconderijo social da exclusão e da não aceitação. É preciso aceitar, tratar, educar.

Em outra situação, o entendimento é de que a família sofre e que é compreendida. O ressentimento reside no diagnóstico médico, na imputação de uma deficiência, um processo de fuga dos rótulos sociais que a escola tenta conter e ressignificar por meio dos AEE. O professor aponta que "Com algumas famílias é um processo lento, às vezes, bem doloroso, por não aceitarem o laudo, quando este é recente; pensam que seu filho será rotulado” (Professora Cidreira, 2019).

É possível notar, nesse caso, que está em operação um governamento que passa por atender a criança e convencer a família de que esses atendimentos são necessários por sugerirem a superação das limitações vistas da perspectiva da escola. O jogo está em andamento, e a ordem do dia diz que é obrigatório incluir e determinar quais deficiências serão atendidas. Nesses movimentos, as vontades também são governadas e educadas e, para isso, todos os recursos à disposição da escola são acionados.

Trata-se de um exercício de poder que é "constituído por uma rede fina, diferenciada, contínua, onde se disseminam as diversas instituições da justiça, da política, da medicina, da psiquiatria" (FOUCAULT, 2001, p. 122). Essa rede é percebida em muitos dizeres dos professores, e o atravessamento das políticas, da medicina e da psiquiatria como ferramentas de convencimento e regulação é evidente. No excerto seguinte, é possível perceber as marcas desses saberes diversos:

Quando a gente percebe que tem descrições de baixa autoestima, a gente fala com a orientação e com a família, a gente procura investigar o porquê, a gente trabalha mais a questão de conversar, comigo ou com a orientação. E quanto ao cuidado mais específico 
com o corpo, depende do contexto familiar, porque às vezes a família também cansa, então a gente tem que buscar essa família também, e para criança, a gente às vezes têm que mostrar na prática como que faz e não só os comandos, cada criança tem o seu tempo pro seu aprendizado (Professora Balneário Pinhal, 2019).

Mesmo com a ciência de que cada criança tem seu tempo, "O aluno deverá aprender o código dos sinais e atender automaticamente a cada um deles" (FOUCAULT, 2002b, p. 140). A família é um ponto de interlocução importante para que os processos de escolarização na perspectiva da inclusão se efetivem, uma vez que fazem uma ponte entre a medicina, a psicologia e o serviço de AEE. A partir dessa ponte, mantêm-se o controle e a captura dessas famílias dentro de um sistema de governamento que opera sobre os entendimentos de inclusão e seus desdobramentos, como um processo de "retomar num outro aspecto a questão da governamentalidade: o governo de si por si” (FOUCAULT, 1997, p. 111). Esse governo passa pela captura e pelo convencimento da família, para que ela aceite o jogo da inclusão.

Tem aquela família que segura, pra preservar, tem aquele professor que acha que eles não vão ter aquilo ali, mas vão. [...] É bem difícil, porque as famílias passam muito trabalho com todas as deficiências, principalmente quando tu vê que teu filho não é aceito (Professora Osório, 2019).

Essas famílias são alvo das políticas de inclusão, tanto quanto as crianças com deficiência, pois "quem quiser ser capaz de governar o Estado deve primeiro saber governar a si mesmo; depois, num outro nível, governar sua família, seu bem, seu domínio; por fim, chegará a governar o Estado" (FOUCAULT, 2008b, p. 125). Não se trata apenas de incluir, mas de fazer aprender e produzir, de criar regramentos e condições de possibilidades para que essas crianças (futuros adultos) tornem-se trabalhadores, parte do jogo econômico.

Não é uma concepção da força de trabalho, é uma concepção de capital-competência, que recebe, em função de variáveis diversas, certa renda que é um salário, uma renda salário, de sorte que é o próprio trabalhador que aparece como uma espécie de empresa para si mesmo. [...] Uma economia feita de unidades-empresas, uma sociedade feita de unidades-empresa (FOUCAULT, 2008a, p. 310).

Contudo, falhas na rede podem criar rupturas nos serviços, na captura dos sujeitos e no investimento dessas empresas de si mesmo. O excerto seguinte mostra 
um pouco dessa realidade, que é característica da região: "A família tem dificuldades de manter os atendimentos. No município não tem centro de atendimento onde as famílias possam ser acolhidas [...] dificuldade de acompanhamento médico" (Professora Balneário Pinhal, 2019).

Para o exercício de governamento ser efetivo, percebe-se que é necessário combater as rupturas da rede de forma que os processos inclusivos se efetivem e que as crianças tenham todos os atendimentos possíveis. A condução das condutas, nesse caso, dá-se pela captura das famílias e pelos constantes registros e encaminhamentos para a rede de apoio como condicionante dos atendimentos - um governamento pela aprendizagem (LOCKMANN, 2013).

\section{A deficiência: a distinção entre normal e anormal como marcador do corpo}

No campo de saberes que envolve a educação especial e a inclusão das pessoas com deficiência, o corpo dessas pessoas está implícito em um processo de tratamentos, terapias, adaptações, próteses e tecnologias de acessibilidade. Todavia, não se trata de um corpo implícito, e sim de um que está explicitamente sob a incidência de um poder que atende às demandas econômicas de mercado. Tal qual apontou e registrou Foucault na história, é possível olhar para esse corpo como força de produção. Os dados da pesquisa trouxeram à tona esse corpo que, no contexto escolar contemporâneo, é alvo de mecanismos de controle e sujeição. Foucault (2001, p. 144) afirmou:

O controle da sociedade sobre os indivíduos não se opera simplesmente pela consciência ou pela ideologia, mas começa no corpo, com o corpo. Foi no biológico, no somático, no corporal que, antes de tudo, investiu a sociedade capitalista. O corpo é uma realidade biopolítica. A medicina é uma estratégia biopolítica.

Logo, a educação inclusiva tornou-se um campo fértil para que as estratégias biopolíticas incidam sobre os corpos com deficiência. Sob as lentes da grade da governamentalidade, foi possível olhar para os caminhos da pesquisa com suspeição, possibilitando a invenção de outras vontades e necessidades investigativas. Então, nesta seção, inspirada por diversas leituras, pode-se perceber também esse corpo. É necessário estabelecer que o corpo ao qual se faz referência é o que Foucault (2002c) 
inscreveu como Anormal, a partir de figuras capturadas pelos dispositivos de poder, desde o período medieval.

Trata-se de criar tessituras sobre um corpo que teve sua presença negada pelo discurso predominante, que teve a existência disciplinada e institucionalizada pela modernidade, e que a sociedade contemporânea quer elevar ao máximo da superação, com referência na norma, e negar, a qualquer custo, as incapacidades/limitações. É um corpo cujo silenciamento apaga as formas disformes da impotência. Esse corpo é nomeado na presente pesquisa de "corpo da deficiência".

Pelbart, sob a ótica da biopolítica, instiga a pensar sobre o corpo considerando a incidência de poder sobre ele. Em um de seus textos, ele afirma:

[...] o poder tomou de assalto a vida. Isto é, o poder penetrou todas as esferas da existência, e as mobilizou inteiramente, e as pôs para trabalhar. Desde os genes, o corpo, a afetividade, o psiquismo, até a inteligência, a imaginação, a criatividade. Tudo isso foi violado, invadido, colonizado; quando não diretamente expropriado pelos poderes (PELBART, 2007, p. 58).

Esses poderes, sob o imperativo de não mais abandonar o corpo disforme, capturaram os corpos da deficiência em instituições normativas, submetendo-os a uma existência de superação das limitações impostas pelas deficiências. É prescrito, dessa forma, um discurso de autonomia e mobilidade vigiada e produtiva, peculiar ao governamento neoliberal, que não só visa ao controle das populações mas também as quer no jogo econômico. Nos ditos dos participantes, essa lógica fica evidenciada:

Como a existência desse corpo em relação ao mundo que ao longo da história estão deixando de ser estigmatizados, desvalorizados, discriminados. 0 aluno conhecerá suas limitações, suas potencialidades, o que irá permitir que o aluno com deficiência se torne crítico, criativo perante a sociedade (Professora Tramandaí, 2019).

O processo se desenrola na história em movimentos que tensionam os poderes e os saberes - e no serviço de AEE não é diferente. Na região, os processos inclusivos ainda são recentes e, portanto, os discursos se produzem e produzem professores que adotam o cuidado de si como ponto de partida.

Em determinados trechos dos dizeres de participantes, podemos denotar a necessidade primeira de cuidar do corpo, deixá-lo desejável ao menos de afetos e tolerância mínima: "E quanto ao cuidado mais específico com o corpo, depende do contexto familiar" (Professora Balneário Pinhal, 2019). A família é convocada ou 
responsabilizada a cumprir com essas metas de asseamentos; a escola, em especial o serviço de AEE, encarrega-se de ensinar os meios pelos quais essas famílias devem atender aos objetivos da ordem do dia.

\begin{abstract}
Mas eu vejo que a evolução deles é bem lenta... O corpo da deficiência talvez seja a relação do aluno com seu próprio corpo? Tem alguns alunos aqui, dos anos iniciais que vem com mau cheiro, piolho, um vem com roupa suja... Eu vejo que esta questão da higiene parece que falta um pouco. Nem todo aluno com deficiência tem uma anomalia. Uma falta de cuidado com o próprio corpo ou de não cuidados da família. É a visão do corpo estranho, eu vejo, assim, não querendo generalizar (Professor Cidreira, 2019).
\end{abstract}

Tendo como percurso o movimento de subjetivação, cabe olhar na história contemporânea os caminhos trilhados pelos dispositivos do biopoder para produzir e alimentar os desejos de superação e produtividade nos corpos da deficiência. Ao longo das transformações do pensamento e da sociedade ocidental, foram percebidas mudanças na forma como o poder incidiu sobre os corpos da deficiência. Foucault (2002c) registrou a invenção de corpos da deficiência no período moderno, após a sociedade perceber a anormalidade como inconveniente a ser corrigido.

Esses sujeitos passaram a ser alvo de estratégias biopolíticas, trocando a incidência de poder que captura e torna o corpo da deficiência um recluso para ser um corpo a ser incluído na esfera social. Essa mudança prescinde de necessidades do Capital, que não quer mais manter o corpo da deficiência escondido e improdutivo. Nesse contexto, surgem fenômenos como a institucionalização e distribuições desses corpos, como analisou Sardagna (2013).

Como um corpo que não atende aos mecanismos de controle e estimulação pode ser produtivo? Interessa transformar corpos disformes em corpos produtivos? A literatura, as políticas públicas e os tratados internacionais afirmam que sim. Diante de tal engendramento, é premente compreender como esses corpos serão convencidos de que precisam abandonar o "quartinho dos fundos" para receber os aplausos da superação. É preciso mudar a ordem do dia e lembrar a esse corpo que ele possui desejos e que deve construir meios para satisfazê-los, criando o que poderia ser uma bioascese ${ }^{1}$ da deficiência ou da superação.

\footnotetext{
${ }^{1}$ Inspirando-se na ascese em Foucault (CASTRO, 2009, p. 45) relaciona-se à "subjetivação de um discurso verdadeiro" sobre o corpo da deficiência.
} 
Tais apontamentos podem ser compreendidos quando se usa como parâmetro o corpo sem deficiência, o corpo humano esperado/previsto, de forma que pareça justificada:

Essa obsessão pela perfectibilidade física, com as infinitas possibilidades de transformação anunciadas pelas próteses genéticas, químicas, eletrônicas ou mecânicas; essa compulsão do eu para causar o desejo do outro por si mediante a idealização da imagem corporal, mesmo que isso custe o bem-estar do sujeito, mesmo que isso o mutile, substitui facilmente a satisfação erótica por uma espécie de mortificação autoimposta (PELBART, 2007, p. 60).

Então, ao olhar para o corpo da deficiência, considerando os governamentos neoliberais, a tarefa é tornar esse corpo um objeto de desejo. É preciso tirá-lo da condição de morto-vivo em que foi mantido por décadas. Trata-se de apagar e negar o corpo incapaz, a fim de convencer o sujeito a submeter esse corpo à máxima produtividade e superação. É preciso seduzir os desejos desse corpo para entrar no jogo de produtividade. É preciso alterar a forma, a afetação causada pelo corpo da deficiência, na perspectiva de que esse corpo perpassa o conceito de "uma vida" de Deleuze (2006), da mesma forma que o moribundo afeta e é afetado pela potência da vida: a vida que insiste em viver, mesmo na impotência do corpo da deficiência. É nesse sentido que o contexto da pesquisa evidencia o potencial da educação inclusiva e especializada como condutor de condutas, permitindo apontar o professor do AEE como acionador de engrenagens biopolíticas.

Esse discurso está presente na ação docente do AEE, conforme este excerto:

[...] sempre tem quem diga: mas não tem cara de autista. Eles não têm cara mesmo, mas tem toda uma peculiaridade de comportamento que tu vês todos os resquícios de uma outra dificuldade. [...] a deficiência é intelectual, não é visível então é mais difícil porque não aparece. Ainda tem professor que diz que eles estão fingindo ou estão usando que são deficientes pra outras coisas. Então o corpo que não aparece é o mais difícil.

Nós precisamos que no final do $3^{\circ}$ ano esse aluno tem que ter um crescimento de conhecimento.

E por mais que tu aches que tá tudo bem, ele sabe que tem diferença. É visível. Fazem a diferença. Apontam a diferença. [...] só que é um corpo de estudo. Um corpo de ver como que está sendo aquele aprendizado, para aquela criança que tem dificuldade e que a gente sabe que muitas coisas eles não vão conseguir. [...] sempre há uma diferença de corpo de pessoa em tamanho, principalmente pelas reprovações. Ele já destoa na sua turma (Professora Osório, 2019).

O profissional figura como um interventor dos corpos da deficiência no ambiente escolar. Esse professor, nesse serviço, configura-se como uma tática de subjetivação dos caminhos da superação a ser conquistada e do enforme desses 
corpos para atender às demandas prescritas. No excerto seguinte, nota-se o entendimento de que o corpo vivido deveria ser priorizado: "Entendo que o corpo vivido das crianças, a corporeidade e a ludicidade devem ser priorizados nas instituições de ensino como se prioriza o desenvolvimento cognitivo" (Professora Balneário Pinhal, 2019).

Uma vez que cabe ao professor convencer o estudante com deficiência a ser produtivo, é preciso tornar este subjetivado por necessidades capitais e de consumo, assim como se deve alimentá-lo com desejos de superação. Tendo esse professor o próprio corpo para alimentar e dele fazer exemplo, então o processo de subjetivação se dá para professor e aluno.

Esse discurso está presente na ação docente do AEE e pode ser relacionado ao que Foucault (2002b) refere:

Não se trata de cuidar do corpo, em massa, grosso modo, como se fosse uma unidade indissociável, mas de trabalhá-lo detalhadamente; de exercer sobre ele uma coerção sem folga, de mantê-lo ao nível mesmo da mecânica - movimentos, gestos, atitudes, rapidez: poder infinitesimal sobre o corpo ativo. [...] Esses métodos que permitem o controle minucioso das operações do corpo, que realizam a sujeição constante de suas forças e Ihes impõem uma relação de docilidade utilidade, são o que podemos chamar as "disciplinas" (FOUCAULT, 2002b, p. 118).

Essas disciplinas aparecem na escola de diversas formas e, no AEE, surgem sob a forma de adaptações curriculares, regulamentos, encaminhamentos e orientações para as famílias. "A disciplina fabrica assim corpos submissos e exercitados, corpos 'dóceis"' (FOUCAULT, 2001, p. 119). A participante do excerto a seguir aponta diversas formas de exercer controle e disciplinamento sobre as crianças com deficiência no serviço de AEE e sobre suas crenças acerca do corpo.

[...] Porque eles ainda não entenderam a deficiência deles, eles podem até entender com o tempo, mais ainda não.

[...] e eles não se veem como diferentes dos outros a não ser que seja físico, não ter as pernas, ou outra coisa.

[...] tu tens que ter pudor com teu corpo, tu não podes mostrar dessa maneira, enfim, tem que conversar, fora que em casa é trabalhado isso.

Que as meninas vão crescendo e vai aparecendo pelo no corpo, e toda a parte anatômica a gente tem que trabalhar com a criança. Eles precisam compreender que vão entrar na puberdade que o corpo se desenvolve, porque o seio cresce, porque vem menstruação pra menina, pro menino a mesma coisa, por que tem ereção.

[...] cada um aprende de um jeito. E cada professor tem um jeito de ensinar [...].

Muitas vezes as crianças já avançaram e regridem, então é uma coisa repetitiva, todo dia, todo dia, sempre, sempre [...]. 
Aqui a gente sabe qual a fase as crianças estão, então às vezes eles estão grandões, são adultos, mas a mentalidade é de criança [...].

[...] por mais que o corpo esteja respondendo de uma maneira, como por exemplo, a puberdade, o corpo está entrando na puberdade, mas a mentalidade, não. Então eles nem sabem às vezes o que estão sentindo (Professora Balneário Pinhal, 2019).

Dessa maneira, todo o esforço e o sentimento expressado na fala da participante é parte de sua sujeição aos discursos que permeiam a inclusão. Segundo Foucault:

Aprender a comportar-se, movimentar-se, ser preciso e ter ritmo. Gestos são fabricados, e sentimentos são produzidos. Este adestramento é resultado da aplicação de técnicas positivas de sujeição baseadas em saberes pedagógicos, médicos, sociológicos, físicos etc. O corpo torna-se útil e eficiente, mas ao mesmo tempo torna-se dócil e submisso: 0 corpo só se torna força útil se é ao mesmo tempo corpo produtivo e corpo submisso (FOUCAULT, 2002b, p. 28).

O olhar e a escrita de Pelbart e de Foucault são bem-vindos na busca por contornos singulares nessa temática. Eles despertam mais vontades do que saciedades e instigam o processo criativo para que outras provocações sejam inscritas, num movimento constante de afetar e ser afetado, e de compreender como os corpos deixam de ser submissos e passam a submeter as suas formas e os seus desejos à ordem do dia.

Pois, se o poder só tivesse a função de reprimir, se agisse apenas por meio da censura, da exclusão, do impedimento, do recalcamento, à maneira de um grande superego, se apenas se exercesse de um modo negativo, ele seria muito frágil. Se ele é forte, é porque produz efeitos positivos no nível do desejo [...] e também no nível do saber. O poder, longe de impedir o saber, o produz. Se foi possível constituir um saber sobre o corpo, foi através de um conjunto de disciplinas militares e escolares. É a partir de um poder sobre o corpo que foi possível um saber fisiológico, orgânico (FOUCAULT, 2001, p. 148-149).

Nesse sentido, cabe entender que todos somos parte de um processo de incidência de poderes imanente, que não está fora do sujeito, mas sim nas relações estabelecidas por ele com o outro e com os mecanismos de subjetivação. Entender que a escrita dessa investigação evidencia a invenção de um serviço que atende às necessidades neoliberais é saber também que produz e reforça discursos que constituem o AEE como uma estratégia de governamento potente, que ganha força e visibilidade com os resultados de trabalhos como esse.

\section{Considerações finais}


A discussão aqui empreendida teve como foco o olhar docente no Atendimento Educacional Especializado e as expectativas em relação aos estudantes, questionando como professores desse serviço de apoio criam/inventam estratégias pedagógicas que incidem no corpo e nas condutas dos estudantes com deficiência em escolas do Litoral Norte do Rio Grande do Sul. O estudo permitiu evidenciar governamentos engendrados nas práticas que incidem sobre os estudantes nos atendimentos em espaços denominados Salas de Recursos Multifuncionais, com ferramentas de análise do campo conceitual foucaultiano, sob a grade de inteligibilidade da governamentalidade. Essa grade nos permitiu olhar para os dados com a noção de que somos conduzidos e condutores de condutas por meio de práticas discursivas que estão presentes em nossas ações e atitudes.

O AEE é um campo de disputa de poderes e saberes diversos, e o desejo de reconhecimento e validação é manifesto nos dizeres dos participantes. Além da evidente associação ao campo da medicina e da psicologia, outras discursividades aparecem nas falas destes e evidenciam que outros discursos midiáticos - como o da máxima produtividade e o da superação das barreiras, sejam elas físicas ou mentais — incidem diretamente no corpo dos sujeitos com deficiência. Produzem desejos e vontades e inventam verdades que transformam os sujeitos com deficiência em um corpo teórico: um corpo imaginário, manipulável e superador contumaz.

\section{Referências}

CASTRO, E. Vocabulário de Foucault - um percurso pelos seus temas, conceitos e autores. Trad. Ingrid M. Xavier. Belo Horizonte: Autêntica Editora, 2009.

DELEUZE, G. Diferença e Repetição. Trad. Luiz Orlandi e Roberto Machado. 2. ed. Graal, 2006. FOUCAULT, M. A verdade e as formas jurídicas. Rio de Janeiro: PUC, 1974.

FOUCAULT, Michel. Subjetividade e verdade (1980-1981). In: FOUCAULT, Michel. Resumo dos Cursos do Collège de France (1970-1982). Rio de Janeiro: Zahar; 1997a, p. 107-115.

FOUCAULT, M. Microfísica do Poder. 16. ed. Trad. Roberto Machado. Rio de Janeiro: Graal, 2001.

FOUCAUlT, M. A Ordem do Discurso. 8. ed. Trad. Laura Fraga de Almeida Sampaio. São Paulo: Loyola, 2002a.

FOUCAULT, M. Vigiar e punir: História da violência nas prisões. 26. ed. Trad. Raquel Ramalhete. Petrópolis: Vozes, 2002b. 
FOUCAULT, M. Os anormais: Curso no College France (1974-1975). Trad. Eduardo Brandão. São Paulo: Martins Fontes, 2002c.

FOUCAULT, M. Nascimento da biopolítica. São Paulo: Martins Fontes, 2008a.

FOUCAULT, M. Segurança, Território, População. Trad. Eduardo Brandão. São Paulo: Martins Fontes, 2008b.

LOCKMANN, K. Medicina e inclusão escolar: estratégias biopolíticas de gerenciamento do risco. In: FABRIS, E. H.; KLEIN, R. R. (orgs.). Inclusão e biopolítica. Belo Horizonte: Autêntica, 2013. p. 129-146.

LOPES, M. C. et al. Inclusão e Biopolítica. Inclusão e Biopolítica: Revista do Instituto Humanitas Unisinos. São Leopoldo, n. 144, p. 3-30, 2010. Disponível em: http://www.ihu.unisinos.br/images/stories/cadernos/ideias/144cadernosihuideias.pdf. Acesso em: 06 maio 2019.

LOPES, M. C.; RECH, T. L. Inclusão, Biopolítica e Educação. Educacão, Porto Alegre, v. 36, n. 2, p. 210-219, maio/ago. 2013. Disponível em: https://revistaseletronicas.pucrs.br/ojs/indexphp/faced/article/view/12942. Acesso em: 25 nov. 2018.

PELBART, P. Biopolítica. Sala Preta, v. 7, p. 57-66, 28 nov. 2007. Disponível em: http://www.revistas.usp.br/salapreta/article/view/57320. Acesso em: 25 nov. 2018.

RAPAPORT, D. Testes de diagnóstico psicológico. Buenos Aires: Editora Paidos, 1965.

SARDAGNA, Helena V. Da institucionalização do anormal à inclusão escolar. In: (orgs.) FABRIS, Elí Henn; Klein, Rejane Ramos. Inclusão e biopolítica. Autêntica, 2013, p. 45-60.

VARELA, J. O Estatuto do Saber Pedagógico. In: SILVA, T. T. (org.). O sujeito da Educação: estudos foucaultianos. 4. ed. Petrópolis: Vozes, 2000. p. 87-96.

VARELA, J.; ALVAREZ-URIA, F. A maquinaria escolar. Teoria e Educação, v. 6, p. 69-97, 1992.

VEIGA-NETO, A. Governo ou Governamento. Revista Curriculo sem Fronteiras, [S.l.], v. 5, n. 2, p. 7985, jul./dez. 2005. Disponível em: http://www.curriculosemfronteiras.org/vol5iss2articles/veiganeto.pdf. Acesso em: 16 jun. 2019.

RECEBIDO: 03/12/2020

APROVADO: 01/06/2021
RECEIVED: $12 / 03 / 2020$

APPROVED: 06/01/2021
RECIBIDO: 03/12/2020

APROBADO: 01/06/2021 